九州大学学術情報リポジトリ

Kyushu University Institutional Repository

\title{
Expression and function of dopamine in odontoblasts
}

Fuj ino, Shoko

Department of Endodontology and Operative Dentistry, Faculty of Dental Science, Kyushu University

Hamano, Sayuri

Department of Endodontology and Operative Dentistry, Faculty of Dental Science, Kyushu University

Tomokiyo, Atsushi

Department of Endodontology, Kyushu University Hospital

Itoyama, Tomohiro

Department of Endodontology and Operative Dentistry, Faculty of Dental Science, Kyushu University

他

http://hdl. hand le. net/2324/2547989

出版情報: Journal of Cellular Physiology. 235 (5)，pp.4376-4387，2019-10-15. Wiley バージョン：

権利関係 : 


\section{Title}

Expression and function of dopamine in odontoblasts

\section{Short running title}

Effects of dopamine on odontoblasts

\section{Authors}

Shoko Fujino ${ }^{1}$, Sayuri Hamano ${ }^{1,2}$, Atsushi Tomokiyo ${ }^{3}$, Tomohiro Itoyama ${ }^{1}$, Daigaku Hasegawa $^{3}$, Hideki Sugii ${ }^{3}$, Shinichiro Yoshida ${ }^{3}$, Ayako Washio ${ }^{4}$, Aoi Nozu ${ }^{1}$, Taiga Ono ${ }^{1}$, Naohisa Wada ${ }^{5}$, Chiaki Kitamura ${ }^{4}$, Hidefumi Maeda ${ }^{1,3}$

${ }^{1}$ Department of Endodontology and Operative Dentistry, ${ }^{2} \mathrm{OBT}$ Research Center, Kyushu University, ${ }^{3}$ Department of Endodontology, Kyushu University Hospital, ${ }^{4}$ Division of Endodontics and Restorative Density, Department of Science of Oral Functions, Kyushu Dental University, ${ }^{5}$ Division of general dentistry, Kyushu University Hospital

\section{* Corresponding author: Hidefumi Maeda, DDS, PhD}

Department of Endodontology and Operative Dentistry

Faculty of Dental Science, Kyushu University

3-1-1 Maidashi Fukuoka 812-8582, Japan.

Phone: +81-92-642-6432

Fax: +81-92-642-6366

E-mail: hide@dent.kyushu-u.ac.jp

\section{Authorship}

Hidefumi Maeda supervised this study. Sayuri Hamano and Atsushi Tomokiyo were involved in drafting this manuscript. Tomohiro Itoyama, Daigaku Hasegawa, Hideki Sugii, Shinichiro Yoshida, Aoi Nozu, Taiga Ono, and Naohisa Wada contributed to acquisition and analysis of data. Ayako Washio and Chiaki Kitamura cultured and analyzed $\mathrm{KN}-3$ cells.

\section{Funding Information}

This study was financially supported by KAKENHI grant numbers (JP19K19031, JP17H01598, and JP17H04385) from the Japan Society for the Promotion of Science. 


\title{
Conflict of Interest
}

The authors declare no conflicts of interest with regard to this article.

\section{Date Sharing and Data Accessibility}

Research data are not shared.

\begin{abstract}
Dopamine (DA) is produced from tyrosine by tyrosine hydroxylase (TH). A recent study has reported that DA promotes mineralization of murine pre-osteoblasts. However, the role of DA in odontoblasts has not been examined. Therefore, in this investigation, we researched the expression of TH and DA in odontoblasts and the effects of DA on the differentiation of pre-odontoblasts (KN-3 cells). Immunostaining showed that TH and DA were intensely expressed in odontoblasts and pre-odontoblasts of rat incisors and molars. KN-3 cells expressed D1-like and D-2 like receptors for DA. Furthermore, DA promoted odontoblastic differentiation of $\mathrm{KN}-3$ cells, whereas an antagonist of D1-like receptors and a PKA signaling blocker, inhibited such differentiation. However, antagonists of D2like receptors promoted differentiation. These results suggested that DA in preodontoblasts and odontoblasts might promote odontoblastic differentiation through D1like receptors, but not D2-like receptors, and PKA signaling in an autocrine or paracrine manner and plays roles in dentinogenesis.
\end{abstract}

\section{Keywords}

Odontoblast, differentiation, dopamine, tyrosine hydroxylase 


\section{Introduction}

Dentin is the major component of teeth and is formed by odontoblasts derived from dental papilla cells (Goldberg et al., 2011; Rothova et al., 2012). Dental papilla cells differentiate into pre-odontoblasts under the influence of enamel proteins secreted by inner enamel epithelial cells and growth factors (e.g. bone morphogenetic protein, fibroblast growth factor, transforming growth factor $\beta-1$, and nerve growth factor) (Mitsiadis \& Pagella, 2016; Niwa et al., 2018; Sagomonyants et al., 2017; Yang et al., 2012), and finally into mature odontoblasts.

Odontoblasts secrete collagenous and non-collagenous proteins that act as scaffolds for mineralization to form dentin. Dentin matrix acidic phosphoprotein 1 (Dmp-1) and Dentin sialophosphoprotein (Dspp), which are extracellular non-collagenous proteins, are essential for dentinogenesis (Butler et al., 1997). Previous studies have reported that Dmp-1 - or Dspp-knockout mice exhibit thin dentin (Gibson et al., 2013). In addition, Nestin is a cytoskeletal protein and neural stem cell marker (Lendahl et al., 1990), which has been reported to be involved in odontoblastic differentiation (Quispe-Salcedo et al., 2012).

When dentin is damaged by caries or trauma resulting in pulp exposure, the application of a pulp-capping material to the exposed site induces the differentiation of pulp cells into odontoblast-like cells to facilitate reparative dentin formation that prevents bacterial infection (Okiji \& Yoshiba, 2009). However, the ideal material to induce the differentiation of odontoblasts according to their differentiation process has not been reported.

Dopamine (DA) is involved in the control of motion, hormone secretion, and differentiation of lymphocytes (Garcia Barrado et al., 2015; Mello et al., 1994; Papa et 
al., 2017; Salamone et al., 2016). It is synthesized by tyrosine hydroxylase (TH) and known as a cathecholamine neurotransmitter and immunomodulator. TH is a rate-limiting enzyme in DA biosynthesis, which is a known sympathetic nerve marker (Joh et al., 1973). Recent studies have reported that DA regulates bone formation. Bliziotes et al. showed that deletion of the DA transporter gene in mice reduces the cancellous bone mass (Bliziotes et al., 2000). Moreover, DA promotes osteoblastic differentiation of murine pre-osteoblasts (Lee et al., 2015) and rat bone marrow mesenchymal stem cells (MSCs) (Lee et al., 2017).

DA binds to DA receptors (DRD1-5) that are classified into either D1-like receptors (DRD1 and DRD5) or D2-like receptors (DRD2-4) (Jaber et al., 1996). Signaling through D1-like receptors activates adenylate cyclase and PKA signaling, whereas the signaling through D2-like receptors suppresses such signaling (Missale et al., 1998). A previous study has shown that PKA signaling promotes osteoblastic differentiation of human MSCs derived from bone marrow (Kim et al., 2013). On the other hand, PKA signaling has been reported to regulate the expression of synthetic enzymes of neurotransmitter and growth factors (Carlezon et al., 2005). A previous study showed that PKA signaling increased the expression of Brain Derived Neurotrophic Factor (BDNF) (Karege et al., 2004) and Th (Kim et al., 1993).

In this study, we hypothesized that TH and DA might be involved in the differentiation of odontoblasts. Therefore, we researched the expression of TH and DA in odontoblasts and the effect of DA on odontoblastic differentiation.

\section{Materials and Methods}

\section{Reagents}


Anti-rat TH and anti-rat DA antibodies were purchased from Abcam (Cambridge, UK). Anti-rat DRD4 antibody was purchased from Invitrogen (Carlsbad, CA, USA). Anti-rat DRD5 antibody was purchased from Bioss (Biosynthesis biotechnology Ltd, Beijing, China). Anti- $\beta$-actin was purchased from Santa Cruz (Santa Cruz Biotechnology, CA). Normal rabbit IgG was purchased from R\&D Systems (Minneapolis, MN, USA). Dopamine hydrochloride, H89 (PKA inhibitor), SCH23390 (Drd1 and Drd5 antagonist), sulpiride (Drd2 and Drd3 antagonist), and clozapine (Drd4 antagonist) were purchased from Sigma Aldrich (St. Louis, MO, USA). An Alexa Fluor 568-conjugated goat anti rabbit antibody was purchased from Invitrogen. Biotinylated anti-rabbit $\operatorname{IgG}$ was purchased from Nichirei (Tokyo, Japan).

\section{Cell culture}

We cultured KN-3 cells in alpha-minimum essential medium ( $\alpha$-MEM; Gibco-BRL, Grand Island, NY, USA) supplemented with $10 \%$ fetal bovine serum (FBS; Biowest, Nuaille, France), designed as $\mathrm{CM}$, at $37^{\circ} \mathrm{C}$ in a humidified atmosphere of $5 \% \mathrm{CO}_{2}$ according to a previous report (Nomiyama et al., 2007) .

\section{Immunohistochemical analysis}

Five-week-old male SD rats were fixed with 4\% paraformaldehyde (PFA; Merck Millipore, Darmstadt, Germany) in phosphate-buffered saline (PBS). Mandibles were decalcified using 10\% ethylenediaminetetraacetic acid (Wako Pure Chemical Industries Ltd., Osaka, Japan) at $4^{\circ} \mathrm{C}$ for 1 month before embedded in paraffin. The tissues were sectioned at $5 \mu \mathrm{m}$ thicknesses. After deparaffinization, the sections were inhibited with 2\% bovine serum albumin (BSA; Nacalai Tesque, Kyoto, Japan) in PBS for 1 hour at 
room temperature and then incubated with an anti-rat TH antibody (1:500; Abcam), antirat DA antibody (1:1000; Abcam), anti-rat DRD4 antibody (1:200; Invitrogen), anti-rat DRD5 antibody (1:400; Bioss), or normal rabbit IgG overnight at $4^{\circ} \mathrm{C}$. After the sections were incubated with biotinylated anti-rabbit IgG (Nichirei Biosciences) for $30 \mathrm{~min}$ at room temperature, they were reacted with an avidin-peroxidase conjugate (Nichirei Biosciences) for $30 \mathrm{~min}$ at room temperature. A simple stain DAB solution (Nichirei Biosciences) visualized positive staining. Nuclei were stained using Mayer's hematoxylin solution (Wako Pure Chemical Industries Ltd). All procedures were approved by the Animal Ethics Committee and conformed to the regulations of Kyushu University.

\section{Immunofluorescence analysis}

We fixed KN-3 cells $\left(8 \times 10^{4}\right.$ cells/dish) cultured in 35-mm dishes (Becton Dickinson Labware, Lincoln Park, NJ) for $24 \mathrm{~h}$ with 4\% PFA and 0.5\% dimethylsulfoxide (Nacalai Tesque) in PBS for 20 min. After blocking with 2\% BSA in PBS for 1 hour, cells were reacted with the anti-rat $\mathrm{TH}$ antibody (1:200), anti-rat DA antibody (1:1000), or normal rabbit IgG overnight at $4^{\circ} \mathrm{C}$. Cells were incubated with Alexa Fluor 568 -conjugated goat anti-rabbit $\operatorname{IgG}(1: 1000$; Invitrogen) for $30 \mathrm{~min}$ at room temperature. Cell nuclei were stained with a 4',6-diamidino-2-phenylindole solution (DAPI; Nacalai Tesque). We observed images using a Biozero digital microscope (Keyence, Osaka, Japan).

\section{Odontoblastic differentiation}

KN-3 cells $\left(2 \times 10^{4}\right.$ cells/well) were seeded on 24 -well plates (Becton Dickinson Labware) and cultured in $\alpha$-MEM containing 5\% FBS and $2 \mathrm{mM} \mathrm{CaCl}_{2}$ as odontoblastic differentiation medium (DM), according to our study (Mizumachi et al., 2017), or DM 
containing DA. After 6 days of cultivation, KN-3 cells were fixed with $10 \%$ formalin for $1 \mathrm{~h}$ and washed with sterile water. Then, they were stained with a $0.3 \%$ Alizarin Red S solution (Sigma-Aldrich) for $1 \mathrm{~h}$. The positive areas of Alizarin Red S-staining were quantified under the Biozero digital microscope. In addition, expression of Dmp-1, Dspp, and Nestin genes was examined by quantitative reverse transcription-polymerase chain reaction (RT-PCR).

\section{Semi-quantitative RT-PCR}

We collected Total RNA from KN-3 cells and rat brain using TRIzol reagent and reverse transcribed by an ExScript RT reagent Kit (Takara Bio Inc., Shiga, Japan), according to the manufacturer's instructions and our recent report (Hamano et al., 2018). PCR was performed in a PCR Thermal Cycler Dice (Takara Bio Inc). PCR conditions were $94^{\circ} \mathrm{C}$ for $2 \mathrm{~min}$ and then the appropriate number of cycles at $94^{\circ} \mathrm{C}$ for $30 \mathrm{~s}$; appropriate annealing temperature for $30 \mathrm{~s} ; 72^{\circ} \mathrm{C}$ for $30 \mathrm{~s}$, and finally $72^{\circ} \mathrm{C}$ for $7 \mathrm{~min}$. Primer sequences, annealing temperatures, cycle numbers, products sizes, and sequence IDs for $\operatorname{Drd1}, \operatorname{Drd2}, \operatorname{Drd3}, \mathrm{Drd4}, \mathrm{Drd5}$, and Gapdh are shown in Table 1. Gapdh was used as an internal control. The PCR products were separated by electrophoresis on $2 \%$ agarose gels (Seakem ME; BioWhittaker Molecular Applications, Rockland, ME, USA) containing ethidium bromide.

\section{Quantitative RT-PCR}

PCR assays were performed using KAPA Express Extract (Kapa Biosystems, Woburn, MA, USA) in a Thermal Cycler Dice Real Time System (Takara Bio Inc). PCR conditions were $95^{\circ} \mathrm{C}$ for $10 \mathrm{~s} ; 45$ cycles at $95^{\circ} \mathrm{C}$ for $5 \mathrm{~s}$, and $60^{\circ} \mathrm{C}$ for $30 \mathrm{~s}$; dissociation cycle at 
$95^{\circ} \mathrm{C}$ for $15 \mathrm{~s}, 60^{\circ} \mathrm{C}$ for $30 \mathrm{~s}$, and $95^{\circ} \mathrm{C}$ for $15 \mathrm{~s}$. The expression levels of target genes were determined by their $\Delta \Delta C_{\mathrm{t}}$ values. Primer sequences, annealing temperatures, cycle numbers, products sizes, and sequence IDs for Bdnf, Dmp-1, Dspp, Nestin, Th, and Gapdh are shown in Table 2. Gapdh was used as an internal control.

\section{Cell proliferation assay}

KN-3 cells $\left(3 \times 10^{3}\right.$ cells/well $)$ were cultured on 48-well plates (Becton Dickinson Labware) for 24, 48, 72, and $96 \mathrm{~h}$ in CM with or without DA, H89, sulpiride and clozapine, or SCH23390. The cell proliferation rate was observed using a Premix WST-1 Cell Proliferation Assay System (Takara Bio Inc), according to the manufacturer's instructions.

\section{Western blotting analysis}

Protein was collected from KN-3 cells using Pierce RIPA Buffer (Invitrogen). The $15 \mu \mathrm{g}$ protein per lane were separated by electrophoresis on $10 \%$ sodium dodecyl sulfatepolyacrylamide gel and transferred onto Immune-Blot PVDF membranes (Bio-Rad Laboratories). After blocking with 5\% skim milk (Yukijirushi, Tokyo, Japan) for 1 hour at room temperature, the membranes were reacted with the anti- $\beta$-actin antibody $(1: 1000)$, anti-DRD4 antibody (1:500), or anti-DRD5 antibody (1:300) overnight at $4{ }^{\circ} \mathrm{C}$. These membranes were incubated with biotinylated anti-mouse IgG (Nichirei Biosciences) or anti-rabbit IgG (Nichirei Biosciences), and then reacted with an avidin-peroxidase conjugate (Sigma-Aldrich). The ECL select Western blotting detection system (GE Healthcare, Buckinghamshire, UK) visualized the reactive bands. We observed the images using Image Quant LAS 500 (GE Healthcare). 


\section{Statistical analysis}

All values are expressed as the mean \pm standard deviation. Statistical analyses were performed using one-way ANOVA followed by Tukey's test for four comparisons or the Student's unpaired t-test. A probability value of $p<0.05$ was considered as statistically significant.

\section{Results}

\section{TH and DA expression in dental pulp tissues of the rat mandibular first molar} Immunohistochemical staining showed that odontoblasts had intensely positive reactions against the anti-TH antibody (Figure 1a, b) and anti-DA antibody (Figure 1e, f). In addition, odontoblastic processes exhibited clear reactions. However, pulp cells had faintly positive staining. Normal control IgG displayed no positive reactions (Figure 1c, $\mathrm{d}, \mathrm{g}, \mathrm{h})$.

\section{TH and DA expression in rat dental pulp tissues of the mandibular incisor}

To assess TH and DA expression dependent on the differentiation stage of odontoblasts, we performed immunohistochemical staining of $\mathrm{TH}$ and DA in pulp tissue of the rat mandibular incisor. Pre-odontoblasts as well as mature odontoblasts showed intensely positive reactions against the anti-TH antibody (Figure 2a, c-e) and anti-DA antibody (Figure 2g, i-k), while no positive staining was observed in the cervical loop (Figure 2f, 1). Normal control IgG showed no positive reactions (Figure $2 b, h$ ).

\section{Expression of TH, DA, and DA receptors in $\mathrm{KN}-3$ cells}

$\mathrm{TH}$ and DA expression in $\mathrm{KN}-3$ cells, which are pre-odontoblasts, was analyzed by 
immunofluorescence staining. $\mathrm{KN}-3$ cells showed intensely positive reactions against the anti-TH antibody (Figure 3a) and anti-DA antibody (Figure 3b). Normal control IgG showed no positive reactions (Figure 3c).

Next, the gene expression of DA receptors in $\mathrm{KN}-3$ cells was analyzed by semiquantitative RT-PCR. KN-3 cells expressed Drd1, Drd3, Drd4, and Drd5, but not Drd2 (Figure 3d). DNA from a rat brain was used as a positive control. Of D-1 like receptors, Drd5 was highly expressed compared with $\operatorname{Drdl}$, while of D-2 like receptors, the expression level of $\mathrm{Drd} 4$ was the highest. Western botting analysis also demonstrated the expression of Drd4 and Drd5 in KN-3 cells (Figure 3e).

\section{Expression of DA receptors in dental pulp tissues of the rat maxillary first molar and the rat mandibular incisor}

Following the above results, we examined the expression of Drd4 and Drd5 in rat pulp tissue. Immunohistochemical staining showed the intense expression of Drd4 (Figure 4a, b, i, k-m) and Drd5 (Figure 4e, f, o, q-s) in pre-odontoblasts and odontoblasts. In addition, we found partially positive reaction against the anti-DRD4 antibody (Figure 4n) and antiDRD5 antibody (Figure 4t) in cervical loop. Normal control IgG showed no positive reactions (Figure 4c, d, g, h, j, p).

\section{Effects of DA on odontoblastic differentiation of $\mathrm{KN}-3$ cells}

After culture in DM with 0,1,10, and $100 \mu \mathrm{M}$ DA for 6 days, KN-3 cells were subjected to Alizarin Red S staining. The Alizarin Red S-stained area of KN-3 cells cultured in DM containing $>1 \mu \mathrm{M}$ DA was significantly greater than that of $\mathrm{KN}-3$ cells cultured in DM alone, whereas no significant difference was found between DM containing 1, 10, or 100 
$\mu \mathrm{M}$ (Figure 5a, b). Similarly, the expression of odontoblastic markers (Dmp-1, Dspp, and Nestin) was also significantly increased in the presence of $10 \mu \mathrm{M}$ DA (Figure $5 \mathrm{c}$ ). KN-3 cells cultured in CM containing with $10 \mu \mathrm{M}$ DA had no significant change in their proliferation rate compared with those cultured in CM (Supporting Information Figure 2a).

Effects of DA receptor antagonists on odontoblastic differentiation of DA-treated KN-3 cells

We investigated whether DA promotes odontoblastic-like differentiation of KN-3 cells through DA receptors using D1-like receptor antagonist SCH23390 and D2-like receptor antagonists sulpiride and clozapine. KN-3 cells were cultured in DA-containing DM with or without $\mathrm{SCH} 23390(0.1,1$, and $10 \mu \mathrm{M})$ or sulpiride $(0.1,1$, and $10 \mu \mathrm{M})$ and clozapine $(0.001,0.01$, and $0.1 \mu \mathrm{M})$. After 6 days of cultivation, Alizarin Red S staining was performed. $10 \mu \mathrm{M} \mathrm{SCH} 23390$ significantly inhibited mineralization in DA-treated $\mathrm{KN}-3$ cells compared with other groups, while $10 \mu \mathrm{M}$ sulpiride and $0.1 \mu \mathrm{M}$ clozapine induced calcification compared with other groups. (Supporting Information Figure 1a-d). We also found no effects of these antagonists on KN-3 cell proliferation (Supporting Information Figure 2b, c).

$\mathrm{DM}$ and $10 \mu \mathrm{M}$ SCH23390-treated cells showed similar mineralization levels, whereas DA treatment significantly increased mineralization that was blocked by $10 \mu \mathrm{M}$ SCH23390 treatment (Figure 6a, b). Moreover, the expression of Dmp-1, Dspp, and Nestin in KN-3 cells cultured under the same conditions showed similar patterns to the mineralization (Figure 6c). However, treatment with sulpiride and clozapine, D2-like receptors antagonists, further induced mineralization and the gene expression of Dmp-1, 
Dspp, and Nestin in DA-treated KN-3 cells (Figure 7a-c).

\section{Effect of the PKA signaling inhibitor on odontoblastic differentiation of DA-treated} KN-3 cells

We examined the expression of Bdnf and Th which was induced in the downstream of PKA signaling to elucidate if PKA signaling was involved in odontoblastic differentiation of DA-treated KN-3 cells. $10 \mu \mathrm{M} \mathrm{SCH} 23390$ decreased the expression of these genes in KN-3 cells induced by DA, while $10 \mu \mathrm{M}$ sulpiride and $0.1 \mu \mathrm{M}$ clozapine increased (Figure $6 d, 7 d)$.

KN-3 cells, furthermore, were cultured in DM with or without DA and/or H89 (0.01, 0.1 , and $1 \mu \mathrm{M}$ ), a PKA inhibitor. After 6 days of cultivation, Alizarin Red S staining was performed. $1 \mu \mathrm{M}$ H89 significantly decreased positive areas of Alizarin red S-staining in DA-treated KN-3 cells compared with other groups (Supporting Information Figure 1e,

f). Then, the proliferation of $\mathrm{KN}-3$ cells cultured in $\mathrm{CM}$ with or without $1 \mu \mathrm{M}$ H89 using the WST-1 assay was examined. KN-3 cells cultured in CM containing $1 \mu \mathrm{M}$ H89 showed no significant difference compared with those cultured in CM (Supporting Information Figure 2d).

One $\mu \mathrm{M}$ H89 treatment significantly reduced the formation of mineralized deposits induced by DA treatment (Figure 8a, b) and the expression of not only Bdnf and Th but Dmp-1, Dspp, and Nestin in KN-3 cells cultured under the same conditions showed similar results to the mineralization (Figure $8 \mathrm{c}$ ).

\section{Discussion}

In this study, we first clarified the expression of both $\mathrm{TH}$ and DA in pre-odontoblasts and 
mature odontoblasts in rat incisors and molars, and found that DA promoted odontoblastic differentiation of pre-odontoblasts via D1-like receptors probably through PKA signaling. However, D2-like receptors might downregulate excess differentiation induced by DA. This mechanism may be a requisite for dentinogenesis.

Expression of TH and DA has been observed in various tissues such as the brain and heart (Lopez-Sanchez et al., 2010). Several reports have examined the expression of TH and DA in dental pulp (Casasco et al., 1995; Schachman et al., 1995). However, it had not been elucidated whether odontoblasts express $\mathrm{TH}$ and $\mathrm{DA}$. Our present study demonstrated that pre-odontoblasts and mature odontoblasts highly expressed TH and DA compared with pulp cells, while no expression was observed in the cervical loop. Therefore, TH and DA expression might be upregulated dependently on the odontoblastic differentiation stage.

Although DA promotes the differentiation of neural cells and striatal neurons (Ohira et al., 2019; Schmid et al., 1998), several reports have shown that DA enhances the differentiation of non-neural cells. DA treatment promotes cardiac muscle cell differentiation of early chick embryo cells (Sarasa \& Climent, 1991) and osteoblastic differentiation of MC3T3-E1 cells (Lee et al., 2015). In the present study, we found that DA treatment promoted mineralization and the expression of odontoblast-related genes in $\mathrm{KN}-3$ cells. In addition, we found expression of DA in KN-3 cells. Baudry et al. reported that DA released from injury-activated platelets is important to recruit dental pulp stem cells after pulp injury (Baudry et al., 2015). Taken together, we assumed that DA released from pre-odontoblasts or odontoblasts might promote odontoblastic differentiation in an autocrine or paracrine manner during dentinogenesis.

Previous studies have shown that DRD1 and DRD5 are involved in $\mathrm{CD}^{+}$helper T 
cell differentiation (Mori et al., 2013), and that DRD2 and DRD3 receptors play an important role in T cell adhesion to fibronectin (Yu et al., 2014). Furthermore, DRD4 is essential for the proliferation and migration of vascular smooth muscle cells (Levite et al., 2001). Additionally, stem cells in dental pulp express Drd1 and Drd3 (Baudry et al., 2015). In this study, we demonstrated that KN-3 cells expressed $\operatorname{Drd1}, \operatorname{Drd} 3, \operatorname{Drd} 4$, and $\operatorname{Drd} 5$ and the protein of Drd4 and Drd5, and that pre-odontoblasts and odontoblasts also clearly expressed Drd4 and Drd5 in rat molars and incisors. We also found that the signal of D1like receptors contributed to odontoblastic differentiation induced by DA, but the signal of D2-like receptors suppressed such differentiation. These results suggest the regulation of dentinogenesis by DA through D1 - and D2-like receptors.

Schmidt et al. demonstrated that stimulation of D1-like receptors and the cAMP/PKA signaling pathway causes the differentiation of striatal neurons in the presence of DA (Schmidt et al., 1998). Our study also revealed the involvement of PKA signaling in odontoblastic differentiation of DA-treated KN-3 cells. Therefore, DA might induce odontoblastic differentiation of immature pulp cells through D1-like receptors via PKA signaling.

Based on these results, we believe that DA could be a new factor involved in dentinogenesis and be applied as a new dental pulp capping reagent which induce reparative dentin formation. Further research is needed to confirm these efficiencies of DA.

\section{Acknowledgements}

The authors acknowledge Drs A. Mai, K. Ipposhi, K. Yamashita, H. Kaneko, O. Adachi, M. Kadowaki, and R. Sugiura for their support. We also thank Mitchell Arico from Edanz Group (www.edanzediting.com/ac) for editing a draft of this manuscript. This study was 
financially supported by KAKENHI grant numbers (JP19K19031, JP17H01598, and JP17H04385) from the Japan Society for the Promotion of Science.

\section{References}

Baudry, A., Alleaume-Butaux, A., Dimitrova-Nakov, S., Goldberg, M., Schneider, B., Launay, J. M., \& Kellermann, O. (2015). Essential Roles of Dopamine and Serotonin in Tooth Repair: Functional Interplay Between Odontogenic Stem Cells and Platelets. Stem Cells, 33(8), 2586-2595. doi:10.1002/stem.2037

Bliziotes, M., McLoughlin, S., Gunness, M., Fumagalli, F., Jones, S. R., \& Caron, M. G. (2000). Bone histomorphometric and biomechanical abnormalities in mice homozygous for deletion of the dopamine transporter gene. Bone, 26(1), 15-19.

Butler, W. T., Ritchie, H. H., \& Bronckers, A. L. (1997). Extracellular matrix proteins of dentine. Ciba Found Symp, 205, 107-115; discussion 115-107.

Carlezon, W. A., Jr., Duman, R. S., \& Nestler, E. J. (2005). The many faces of CREB. Trends Neurosci, 28(8), 436-445. doi:10.1016/j.tins.2005.06.005

Casasco, A., Frattini, P., Casasco, M., Santagostino, G., Springall, D. R., Kuhn, D. M., \& Polak, J. M. (1995). Catecholamines in human dental pulp. A combined immunohistochemical and chromatographic study. Eur J Histochem, 39(2), 133140.

Garcia Barrado, M. J., Iglesias Osma, M. C., Blanco, E. J., Carretero Hernandez, M., Sanchez Robledo, V., Catalano Iniesta, L., . . . Carretero, J. (2015). Dopamine modulates insulin release and is involved in the survival of rat pancreatic beta cells. PLoS One, 10(4), e0123197. doi:10.1371/journal.pone.0123197

Gibson, M. P., Zhu, Q., Wang, S., Liu, Q., Liu, Y., Wang, X., . . Lu, Y. (2013). The rescue of dentin matrix protein 1 (DMP1)-deficient tooth defects by the transgenic expression of dentin sialophosphoprotein (DSPP) indicates that DSPP is a downstream effector molecule of DMP1 in dentinogenesis. J Biol Chem, 288(10), 7204-7214. doi:10.1074/jbc.M112.445775

Goldberg, M., Kulkarni, A. B., Young, M., \& Boskey, A. (2011). Dentin: structure, composition and mineralization. Front Biosci (Elite Ed), 3, 711-735.

Hamano, S., Tomokiyo, A., Hasegawa, D., Yoshida, S., Sugii, H., Mitarai, H., . . Maeda, H. (2018). Extracellular Matrix from Periodontal Ligament Cells Could Induce the Differentiation of Induced Pluripotent Stem Cells to Periodontal Ligament Stem Cell-Like Cells. Stem Cells Dev, 27(2), 100-111. doi:10.1089/scd.2017.0077

Jaber, M., Robinson, S. W., Missale, C., \& Caron, M. G. (1996). Dopamine receptors and brain function. Neuropharmacology, 35(11), 1503-1519. 
Joh, T. H., Geghman, C., \& Reis, D. (1973). Immunochemical demonstration of increased accumulation of tyrosine hydroxylase protein in sympathetic ganglia and adrenal medulla elicited by reserpine. Proc Natl Acad Sci U S A, 70(10), 2767-2771.

Karege, F., Schwald, M., Papadimitriou, P., Lachausse, C., \& Cisse, M. (2004). The cAMP-dependent protein kinase $\mathrm{A}$ and brain-derived neurotrophic factor expression in lymphoblast cells of bipolar affective disorder. J Affect Disord, 79(13), 187-192. doi:10.1016/s0165-0327(02)00463-9

Kim, J. M., Choi, J. S., Kim, Y. H., Jin, S. H., Lim, S., Jang, H. J., . . Suh, P. G. (2013). An activator of the cAMP/PKA/CREB pathway promotes osteogenesis from human mesenchymal stem cells. $J$ Cell Physiol, 228(3), 617-626. doi:10.1002/jcp.24171

Kim, K. S., Park, D. H., Wessel, T. C., Song, B., Wagner, J. A., \& Joh, T. H. (1993). A dual role for the cAMP-dependent protein kinase in tyrosine hydroxylase gene expression. Proc Natl Acad Sci $U$ S A, 90(8), 3471-3475. doi:10.1073/pnas.90.8.3471

Lee, D. J., Lee, Y. T., Zou, R., Daniel, R., \& Ko, C. C. (2017). Polydopamine-Laced Biomimetic Material Stimulation of Bone Marrow Derived Mesenchymal Stem Cells to Promote Osteogenic Effects. Sci Rep, 7(1), 12984. doi:10.1038/s41598017-13326-y

Lee, D. J., Tseng, H. C., Wong, S. W., Wang, Z., Deng, M., \& Ko, C. C. (2015). Dopaminergic effects on in vitro osteogenesis. Bone Res, 3, 15020. doi:10.1038/boneres.2015.20

Lendahl, U., Zimmerman, L. B., \& McKay, R. D. (1990). CNS stem cells express a new class of intermediate filament protein. Cell, 60(4), 585-595.

Levite, M., Chowers, Y., Ganor, Y., Besser, M., Hershkovits, R., \& Cahalon, L. (2001). Dopamine interacts directly with its D3 and D2 receptors on normal human T cells, and activates betal integrin function. Eur J Immunol, 31(12), 3504-3512. doi:10.1002/1521-4141(200112)31:12<3504::AID-IMMU3504gt;3.0.CO;2-F

Lopez-Sanchez, C., Bartulos, O., Martinez-Campos, E., Ganan, C., Valenciano, A. I., Garcia-Martinez, V., . . . Hernandez-Sanchez, C. (2010). Tyrosine hydroxylase is expressed during early heart development and is required for cardiac chamber formation. Cardiovasc Res, 88(1), 111-120. doi:10.1093/cvr/cvq179

Mello, N. K., Mendelson, J. H., Drieze, J. M., Teoh, S. K., Kelly, M. L., \& Sholar, J. W. (1994). Effects of dopamine on prolactin: interactions with cocaine selfadministration by female rhesus monkeys. J Pharmacol Exp Ther, 270(3), 11101120. 
Missale, C., Nash, S. R., Robinson, S. W., Jaber, M., \& Caron, M. G. (1998). Dopamine receptors: from structure to function. Physiol Rev, 78(1), 189-225. doi:10.1152/physrev.1998.78.1.189

Mitsiadis, T. A., \& Pagella, P. (2016). Expression of Nerve Growth Factor (NGF), TrkA, and p75(NTR) in Developing Human Fetal Teeth. Front Physiol, 7, 338. doi:10.3389/fphys.2016.00338

Mizumachi, H., Yoshida, S., Tomokiyo, A., Hasegawa, D., Hamano, S., Yuda, A., . . . Maeda, H. (2017). Calcium-sensing receptor-ERK signaling promotes odontoblastic differentiation of human dental pulp cells. Bone, 101, 191-201. doi:10.1016/j.bone.2017.05.012

Niwa, T., Yamakoshi, Y., Yamazaki, H., Karakida, T., Chiba, R., Hu, J. C., . . . Gomi, K. (2018). The dynamics of TGF-beta in dental pulp, odontoblasts and dentin. Sci Rep, 8(1), 4450. doi:10.1038/s41598-018-22823-7

Nomiyama, K., Kitamura, C., Tsujisawa, T., Nagayoshi, M., Morotomi, T., Terashita, M., \& Nishihara, T. (2007). Effects of lipopolysaccharide on newly established rat dental pulp-derived cell line with odontoblastic properties. $J$ Endod, 33(10), 1187 1191. doi:10.1016/j.joen.2007.05.015

Ohira, K. (2019). Dopamine stimulates differentiation and migration of cortical interneurons. Biochem Biophys Res Commun, 512(3), 577-583. doi:10.1016/j.bbrc.2019.03.105

Okiji, T., \& Yoshiba, K. (2009). Reparative dentinogenesis induced by mineral trioxide aggregate: a review from the biological and physicochemical points of view. Int $J$ Dent, 2009, 464280. doi:10.1155/2009/464280

Papa, I., Saliba, D., Ponzoni, M., Bustamante, S., Canete, P. F., Gonzalez-Figueroa, P., . . Vinuesa, C. G. (2017). TFH-derived dopamine accelerates productive synapses in germinal centres. Nature, 547(7663), 318-323. doi:10.1038/nature23013

Quispe-Salcedo, A., Ida-Yonemochi, H., Nakatomi, M., \& Ohshima, H. (2012). Expression patterns of nestin and dentin sialoprotein during dentinogenesis in mice. Biomed Res, 33(2), 119-132.

Rothova, M., Peterkova, R., \& Tucker, A. S. (2012). Fate map of the dental mesenchyme: dynamic development of the dental papilla and follicle. Dev Biol, 366(2), 244-254. doi:10.1016/j.ydbio.2012.03.018

Sagomonyants, K., Kalajzic, I., Maye, P., \& Mina, M. (2017). FGF Signaling Prevents the Terminal Differentiation of Odontoblasts. J Dent Res, 96(6), 663-670. doi:10.1177/0022034517691732

Salamone, J. D., Yohn, S. E., Lopez-Cruz, L., San Miguel, N., \& Correa, M. (2016). 
Activational and effort-related aspects of motivation: neural mechanisms and implications for psychopathology. Brain, 139(Pt 5), 1325-1347. doi:10.1093/brain/aww050

Sarasa, M., \& Climent, S. (1991). Cardiac differentiation induced by dopamine in undifferentiated cells of early chick embryo. Dev Biol, 148(1), 243-248.

Schachman, M. A., Rosenberg, P. A., \& Linke, H. A. (1995). Quantitation of catecholamines in uninflamed human dental pulp tissues by high-performance liquid chromatography. Oral Surg Oral Med Oral Pathol Oral Radiol Endod, 80(1), 83-86.

Schmidt, U., Pilgrim, C., \& Beyer, C. (1998). Differentiative effects of dopamine on striatal neurons involve stimulation of the cAMP/PKA pathway. Mol Cell Neurosci, 11(1-2), 9-18. doi:10.1006/mcne.1998.0668

Yang, W., Harris, M. A., Cui, Y., Mishina, Y., Harris, S. E., \& Gluhak-Heinrich, J. (2012). Bmp2 is required for odontoblast differentiation and pulp vasculogenesis. J Dent Res, 91(1), 58-64. doi:10.1177/0022034511424409

Yu, C., Wang, Z., Han, Y., Liu, Y., Wang, W. E., Chen, C., . . Zeng, C. (2014). Dopamine $\mathrm{D}(4)$ receptors inhibit proliferation and migration of vascular smooth muscle cells induced by insulin via down-regulation of insulin receptor expression. Cardiovasc Diabetol, 13, 97. doi:10.1186/1475-2840-13-97 


\begin{tabular}{|c|c|c|c|c|c|}
\hline \multirow{2}{*}{$\begin{array}{c}\text { Target gene } \\
\text { (abbreviation) }\end{array}$} & $\begin{array}{c}\text { Forward (top) and reverse (bottom) } \\
\text { primer sequences }\end{array}$ & $\begin{array}{c}\text { Size of } \\
\text { amplified } \\
\text { products } \\
(\mathrm{bp})\end{array}$ & $\begin{array}{c}\text { Annealing } \\
\text { temperature } \\
\left({ }^{\circ} \mathrm{C}\right)\end{array}$ & Cycles & Sequence ID \\
\hline Drd1 & $\begin{array}{c}\text { TGACATCATGTGCTCTACGGC } \\
\text { GAAATGGCATACGTCCTGCTC }\end{array}$ & 288 & 59 & 35 & NM_012546.3 \\
\hline Drd2 & $\begin{array}{c}\text { TTGCCATTGTTCTCGGTGTGT } \\
\text { CCACAGCTTGCAGGGATGAG }\end{array}$ & 227 & 59 & 35 & NM_012547.1 \\
\hline Drd3 & $\begin{array}{c}\text { GGAGCACATAGAAGACAAACAATATCCCCA } \\
\text { CAATGACCACCATCTGGGTGGCCTTCTTCT }\end{array}$ & 338 & 63 & 35 & NM_017140.2 \\
\hline Drd4 & $\begin{array}{c}\text { GATGTGTTGGACGCCTTTCT } \\
\text { CTCGGCATTGAAGATGGTGTA }\end{array}$ & 151 & 56 & 35 & NM_012944.2 \\
\hline Drd5 & $\begin{array}{c}\text { GGAGGAAGGCTGGGAGCTAGAA } \\
\text { GCTGACACAAGGGAAGCCAGTC }\end{array}$ & 403 & 62 & 35 & NM_012768.1 \\
\hline Gapdh & $\begin{array}{c}\text { GCAAGTTCAACGGCACAG } \\
\text { GCCAGTAGACTCCACGACA }\end{array}$ & 140 & 59 & 20 & NM_017008.4 \\
\hline
\end{tabular}

Table 1: primer sequences, annealing temperature, cycle numbers, product sizes, and sequence IDs for semi-quantitative RT-PCR 


\begin{tabular}{|c|c|c|c|c|c|}
\hline $\begin{array}{c}\text { Target gene } \\
\text { (abbreviation) }\end{array}$ & $\begin{array}{c}\text { Forward (top) and reverse (bottom) } \\
\text { primer sequences }\end{array}$ & $\begin{array}{l}\text { Size of } \\
\text { amplified } \\
\text { products } \\
\text { (bp) }\end{array}$ & $\begin{array}{c}\text { Annealing } \\
\text { temperature } \\
\left({ }^{\circ} \mathrm{C}\right)\end{array}$ & Cycles & Sequence ID \\
\hline Bdnf & $\begin{array}{l}\text { AGGAGCCCCATCACAATCTC } \\
\text { GCCAAAAAGAGACCACAGCA }\end{array}$ & 231 & 60 & 40 & NM_001270630.1 \\
\hline Dmp-1 & $\begin{array}{l}\text { TCAGATGACAGCCAGGATGTGGAA } \\
\text { TTTCCTCCTTGGAGCGGAAATCCT }\end{array}$ & 151 & 60 & 40 & NM_203493.3 \\
\hline Dspp & $\begin{array}{l}\text { TCCCACAGAGGGTGGGATTAT } \\
\text { TCTAATCCCTGATTTTGGCTCTG }\end{array}$ & 71 & 60 & 40 & NM_012790.2 \\
\hline Nestin & $\begin{array}{l}\text { AGAGAAGCGCTGGAACAGAG } \\
\text { AGGTGTCTGCAACCGAGAGT }\end{array}$ & 234 & 60 & 40 & NM_001308239.1 \\
\hline Th & $\begin{array}{l}\text { CGGGCTATGTAAACAGAATGG } \\
\text { CACAGGCTGGTAGGTTTGATC }\end{array}$ & 163 & 60 & 40 & NM_012740.3 \\
\hline Gapdh & $\begin{array}{l}\text { GCAAGTTCAACGGCACAG } \\
\text { GCCAGTAGACTCCACGACA }\end{array}$ & 140 & 60 & 40 & NM_017008.4 \\
\hline
\end{tabular}

Table 2: primer sequences, annealing temperature, cycle numbers, product sizes, and sequence IDs for quantitative RT-PCR 

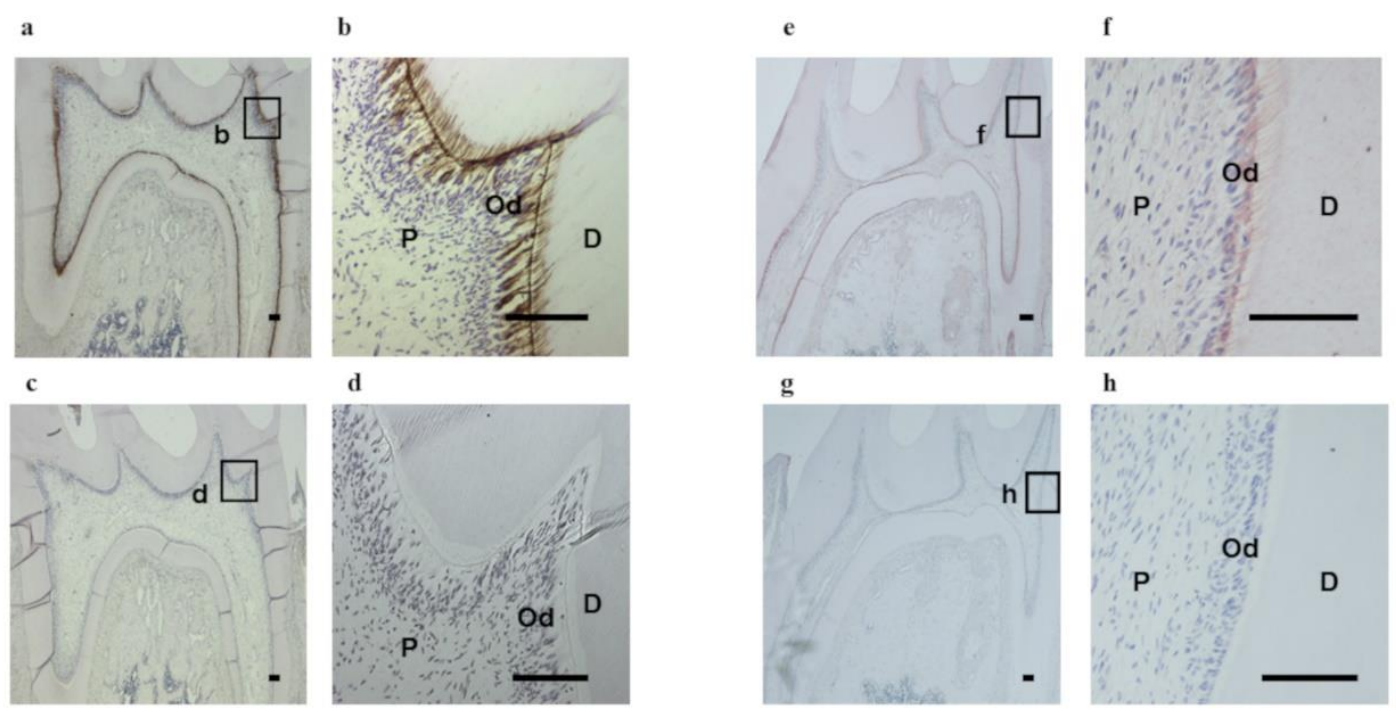

Figure 1 Expression of TH and DA in dental pulp tissues of the rat mandibular first molar. Immunohistochemical staining of sagittal sections of the mandibular first molar from 5 week-old male SD rats by an anti-TH antibody (a, b) and anti-DA antibody (e, f). (b, f) Magnified images of the boxed areas in a, e. $(\mathrm{d}, \mathrm{h})$ Magnified images of the boxed areas in c, g. (c, d, g, h) Rabbit control IgG was used as a negative control. Nuclei were stained with hematoxylin. Bars=100 $\mu \mathrm{m}$; D, dentin; Od, odontoblasts; P, dental pulp. 


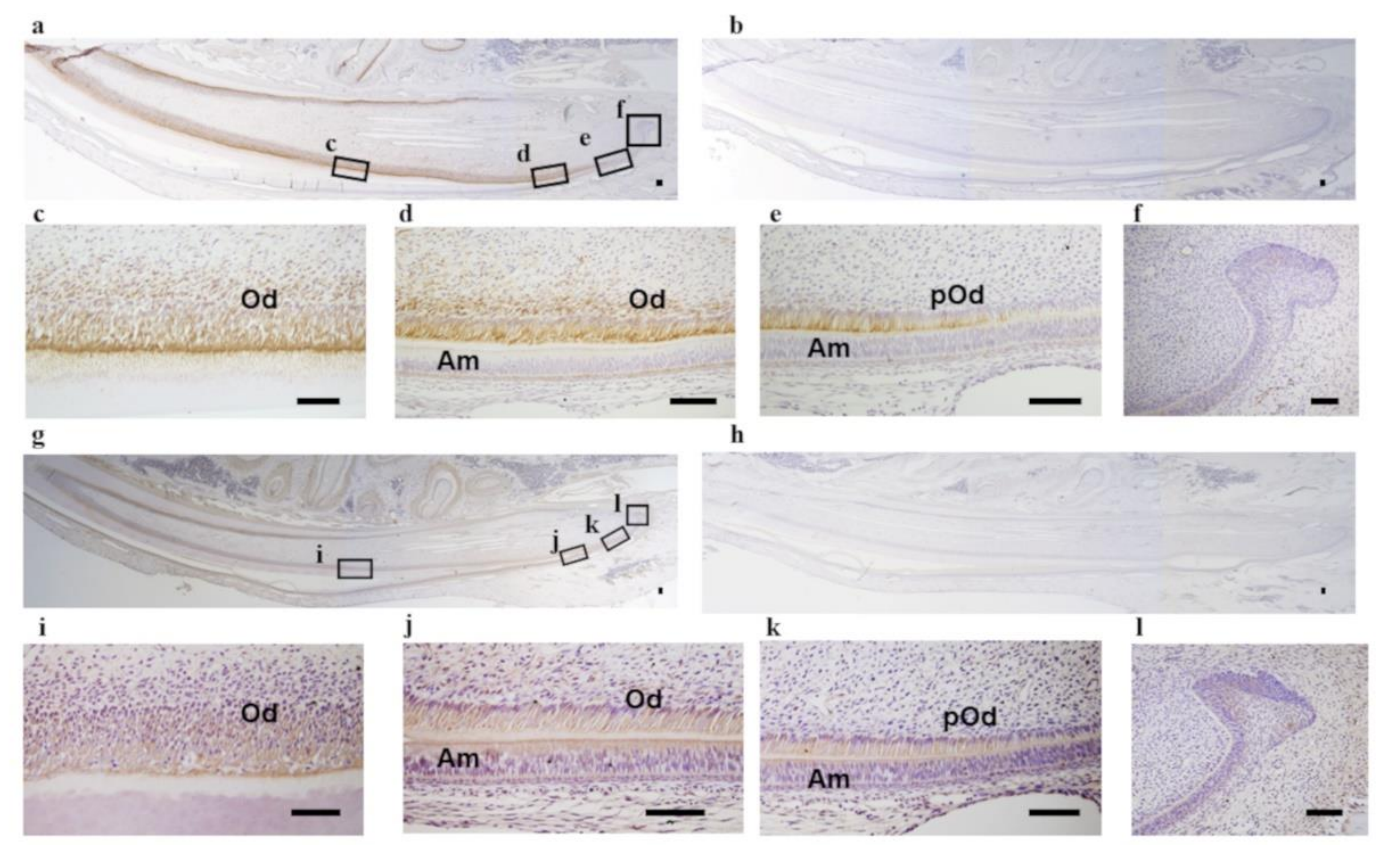

Figure 2 Expression of TH and DA in rat dental pulp tissues of the mandibular incisor. Immunohistochemical staining of the mandibular incisor from 5-week-old male SD rats by the anti-TH antibody (a, c-f) and anti-DA antibody (g, i-l). (c-f) Magnified images of the boxed areas in a. (i-1) Magnified images of the boxed areas in g. (f, l) No positive staining was detected in the cervical loop. $(b, h)$ Rabbit control IgG was used as a negative control. Nuclei were stained with hematoxylin. Bars=100 $\mu \mathrm{m}$; Am, ameloblast; D, dentin; Od, odontoblasts; P: dental pulp; pOd, pre-odontoblasts. 

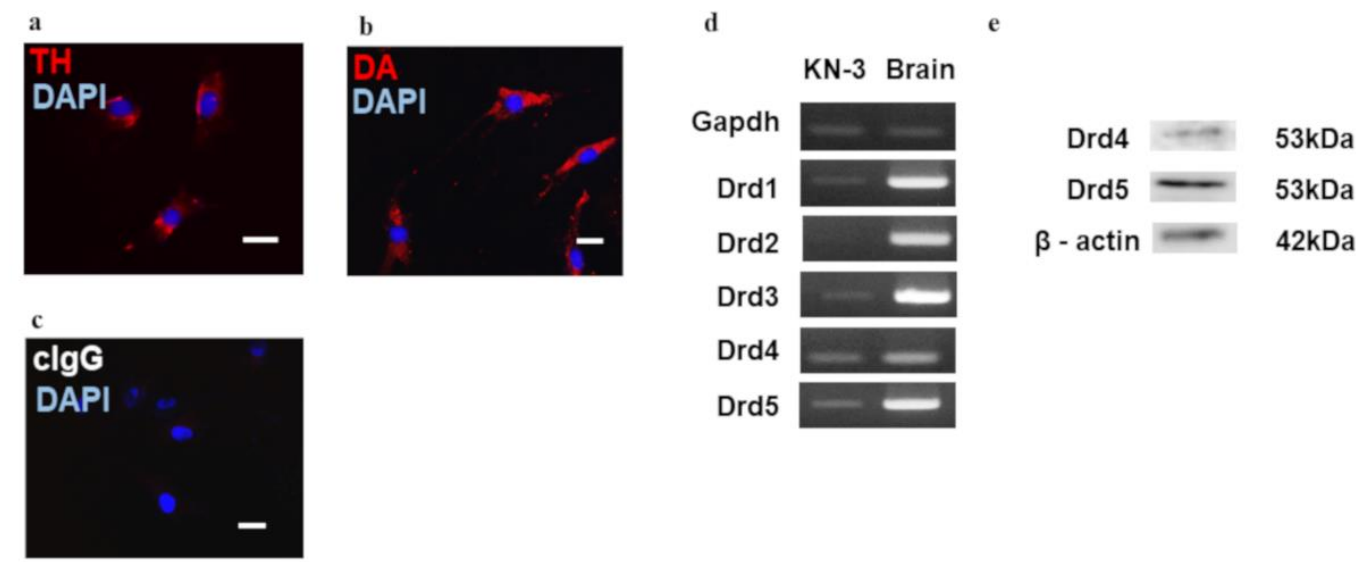

Figure 3 Expression of TH, DA, and DA receptors in KN-3 cells. Immunofluorescence staining of KN-3 cells by the anti-TH antibody (red) (a) and anti-DA antibody (red) (b). (c) Rabbit control IgG (cIgG) was used as a negative control. Nuclei were stained with DAPI (blue). Bars $=50 \mu \mathrm{m}$. (d) Gene expression of DA receptors in KN-3 cells was examined by semi-quantitative RT-PCR. DNA from a rat brain was used as a positive control. (e) Protein expression of Drd4 and Drd5 in KN-3 cells was investigated by Western blotting analysis. 

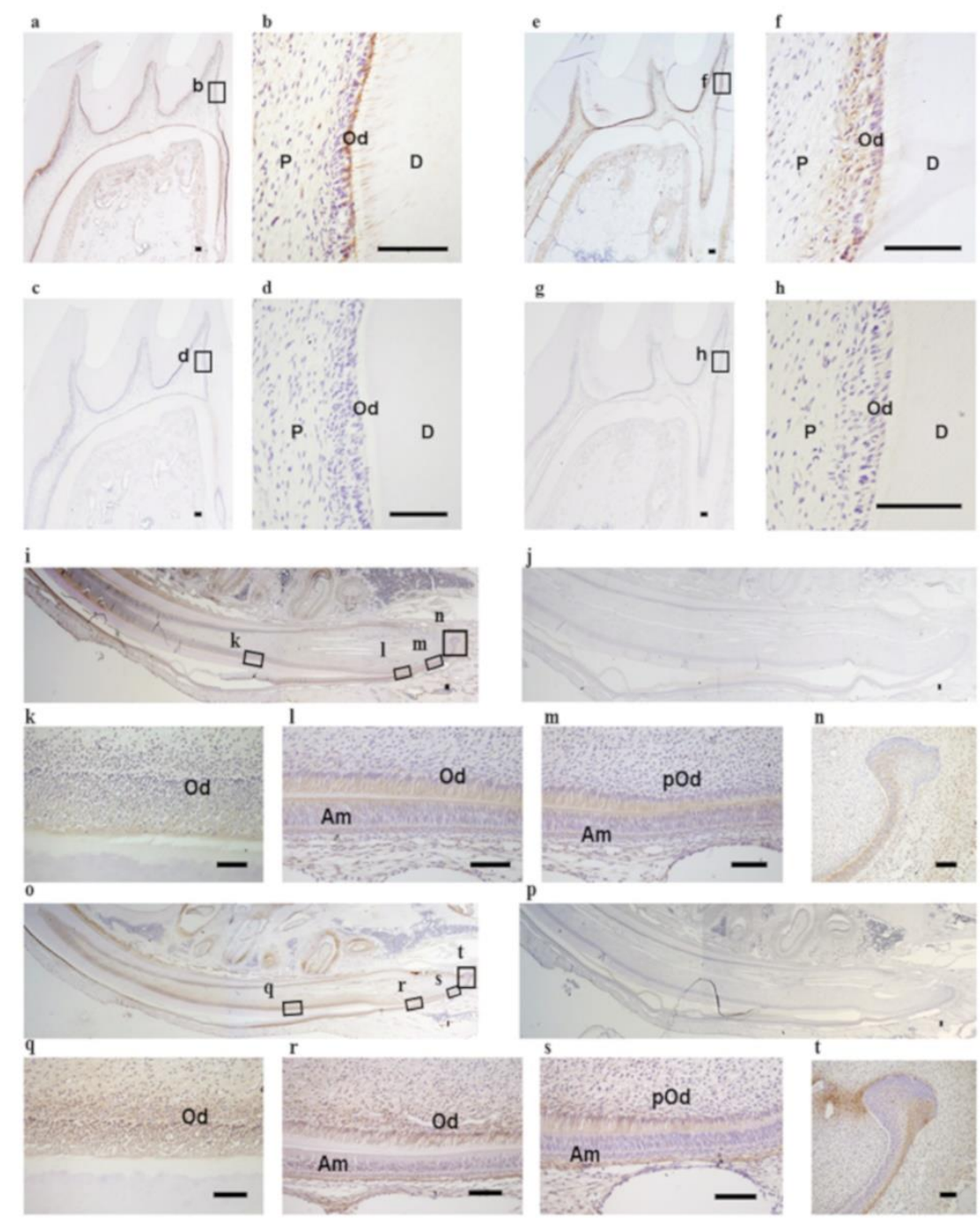

Figure 4 Immunohistochemical staining of sagittal sections of the maxillary first molar from 5-week-old male SD rats (a-h) and the mandibular incisor from 4-week-old male SD rats (i-t) by an anti-DRD4 antibody (a, b, i, k-n) and anti-DRD5 antibody (e, f, o, qt). (b, f) Magnified images of the boxed areas in a, e. (d, h) Magnified images of the boxed areas in c, g. (k-n) Magnified images of the boxed areas in i. (q-t) Magnified images of the boxed areas in $\mathrm{o.}(\mathrm{c}, \mathrm{d}, \mathrm{g}, \mathrm{h}, \mathrm{j}, \mathrm{p})$ Rabbit control IgG was used as a negative control. Nuclei were stained with hematoxylin. Bars=100 $\mu \mathrm{m}$; Am, ameloblast; D, dentin; Od, 
odontoblasts; P, dental pulp; pOd, pre-odontoblasts.

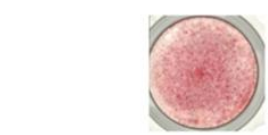

DA $(\mu \mathrm{M})$

0

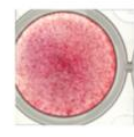

1

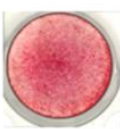

10

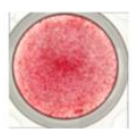

100

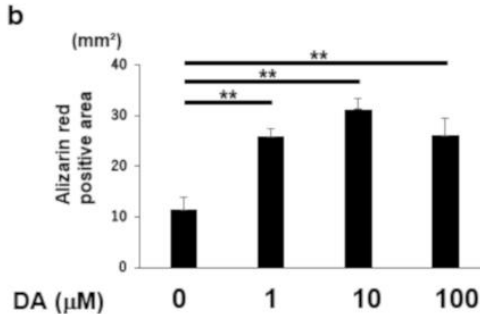

Nestin
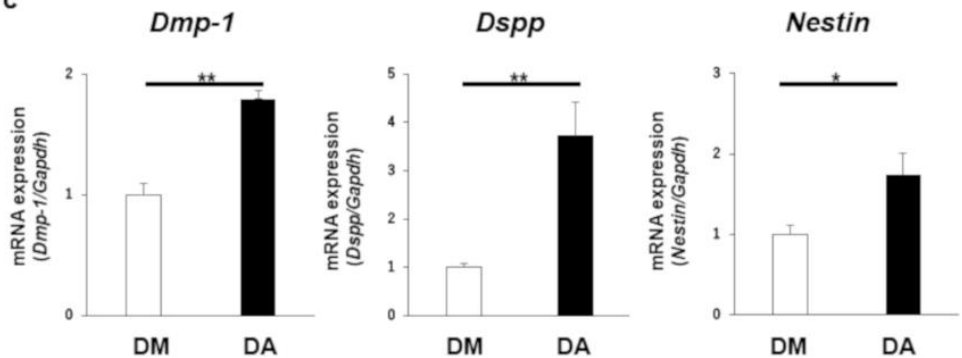

Figure 5 Effect of DA on odontoblastic differentiation of KN-3 cells. (a) Alizarin Red S staining of KN-3 cells cultured in DM containing DA $(0-100 \mu \mathrm{M})$ for 6 days. (b) Positive areas of Alizarin red S-staining were quantified by a Biozero digital microscope. Statistical analysis was performed using one-way ANOVA followed by Tukey's test. (c) Gene expression of Dmp-1, Dspp and Nestin was examined by quantitative RT-PCR. Statistical analysis was performed using the Student's unpaired t-test. Dmp-1: dentin matrix acidic phosphoprotein 1, Dspp: dentin sialophosphoprotein, $\mathrm{n}=3,{ }^{* *} \mathrm{P}<0.01$, ${ }^{*} \mathrm{P}<0.05$. 
a

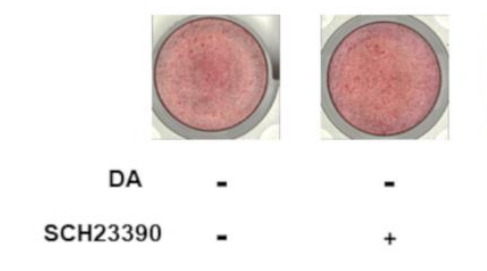

c

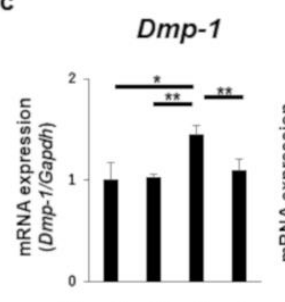

DA $\mathrm{SCH} 23390$

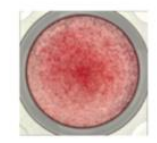

$+$

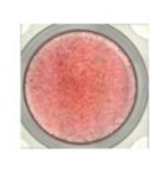

:

$+$

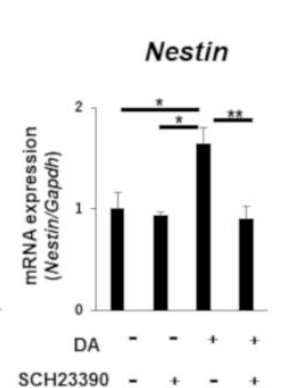

b

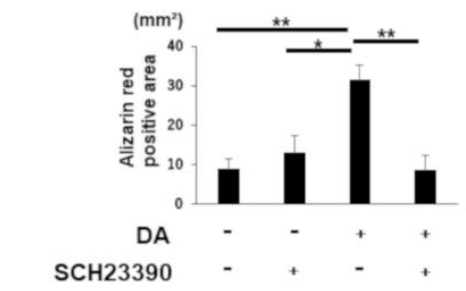

d

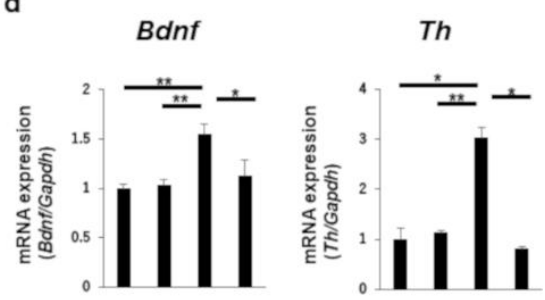

$\mathrm{DA}-\mathrm{C}^{-}++$

Figure 6 Effects of D1-like receptor antagonist on odontoblastic differentiation of DAtreated KN-3 cells. (a) Alizarin red S staining of KN-3 cells cultured in DM or DM containing $10 \mu \mathrm{M}$ DA with or without SCH23390 (10 $\mu \mathrm{M})$. (b) Positive areas of Alizarin red S-staining were quantified using the Biozero digital microscope. Statistical analysis was performed using one-way ANOVA followed by Tukey's test (c, d) Gene expression of Dmp-1, Dspp, Nestin, Bdnf, and Th was examined by quantitative RT-PCR. Statistical analysis was performed using one-way ANOVA followed by Tukey's test. Bdnf: brain derived neurotrophic factor, Th: tyrosine hydroxylase, $\mathrm{n}=3,{ }^{* *} \mathrm{P}<0.01,{ }^{*} \mathrm{P}<0.05$. 

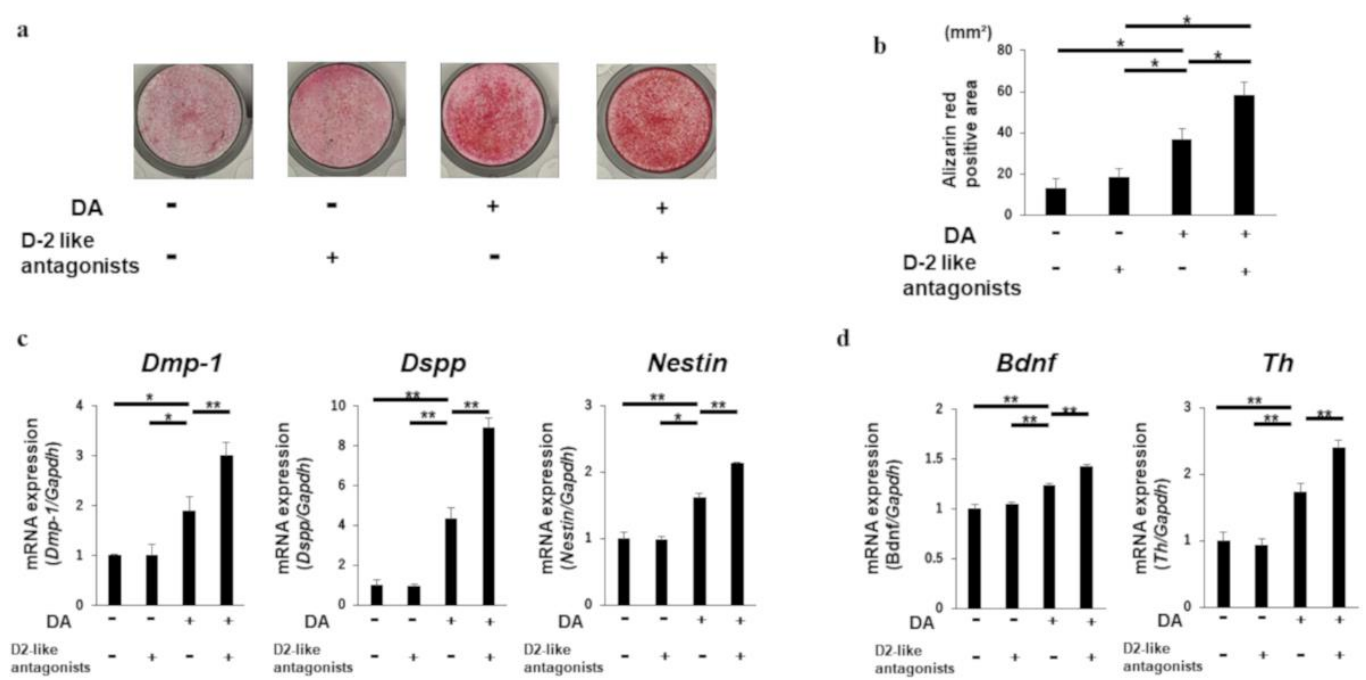

Figure 7 Effects of D2-like receptor antagonists on odontoblastic differentiation of DAtreated KN-3 cells. (a) Alizarin Red S staining of KN-3 cells cultured in DM or DM containing $10 \mu \mathrm{M}$ DA with or without sulpiride $(10 \mu \mathrm{M})$ and clozapine $(0.1 \mu \mathrm{M})$. (b) Positive areas of Alizarin red S-staining were quantified using the Biozero digital microscope. Statistical analysis was performed using one-way ANOVA followed by Tukey's test. (c, d) Gene expression of Dmp-1, Dspp, Nestin, Bdnf, and Th was examined by quantitative RT-PCR. Statistical analysis was performed using one-way ANOVA followed by Tukey's test. $\mathrm{n}=3,{ }^{* *} \mathrm{P}<0.01,{ }^{*} \mathrm{P}<0.05$. 


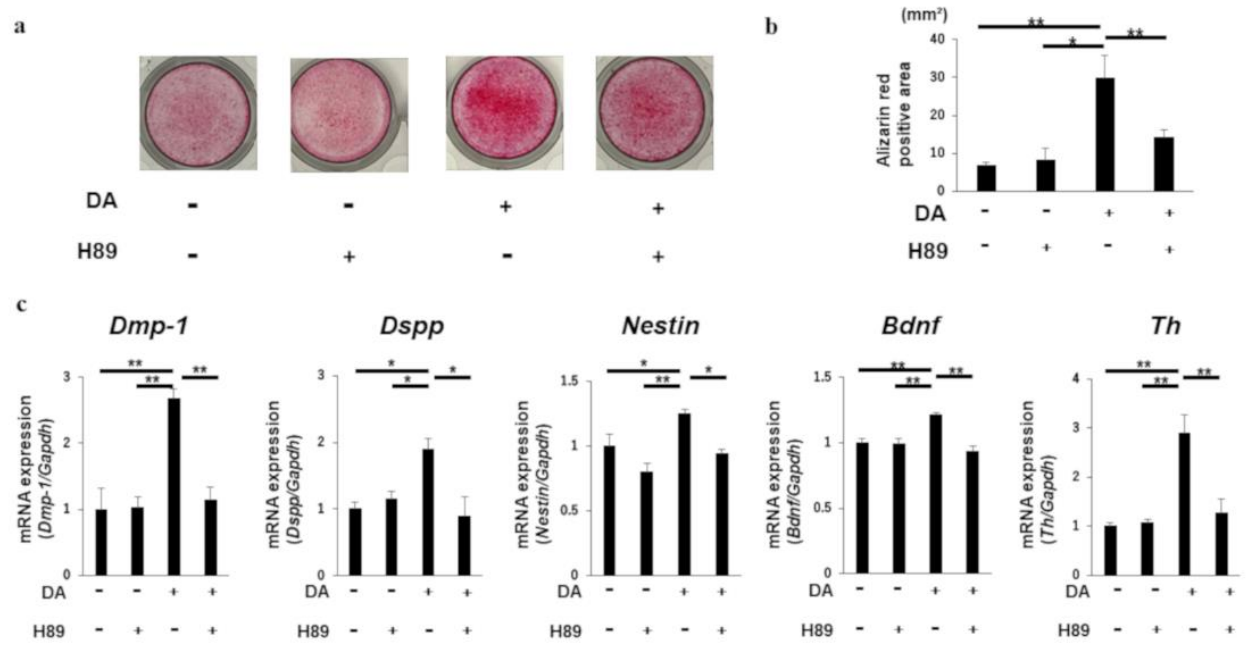

Figure 8 Effects of a PKA signaling inhibitor on odontoblastic differentiation of DAtreated KN-3 cells. (a) Alizarin Red S staining of KN-3 cells cultured in DM or DM containing $10 \mu \mathrm{M}$ DA with or without H89 $(1 \mu \mathrm{M})$. (b) Positive areas of Alizarin red Sstaining were quantified using a Biozero digital microscope. Statistical analysis was performed using one-way ANOVA followed by Tukey's test. (c) Gene expression of Dmp-1, Dspp, Nestin, Bdnf, and Th was examined by quantitative RT-PCR. Statistical analysis was performed using one-way ANOVA followed by Tukey's test. $\mathrm{n}=3,{ }^{* *} \mathrm{P}<0.01$, ${ }^{*} \mathrm{P}<0.05$ 
a

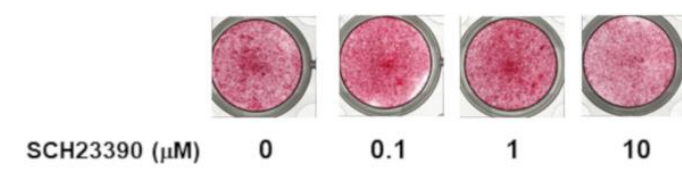

c

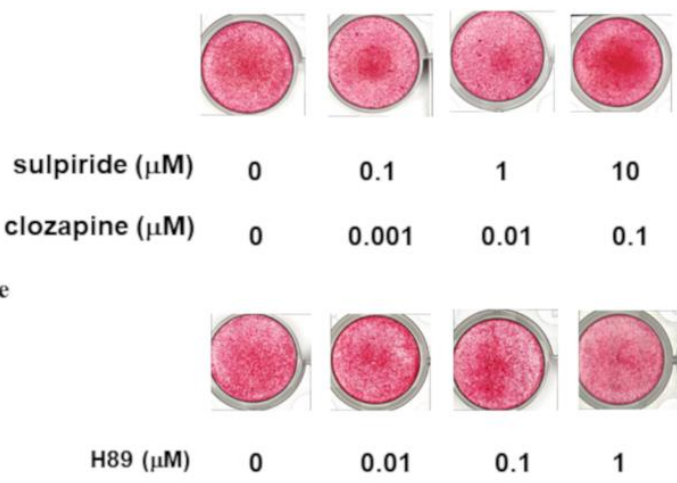

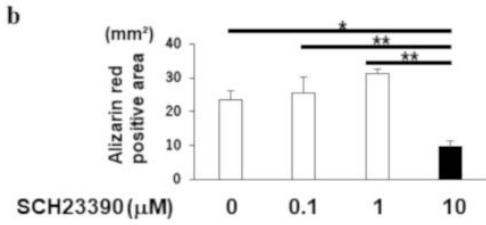

d

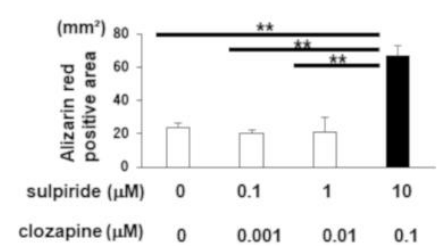

f

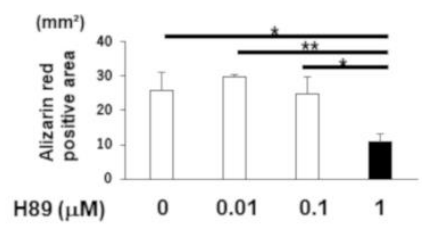

\section{Supporting Information Figure 1}

Effects of the concentrations of SCH23390, sulpiride and clozapine, and H89 on the mineralization of DA-treated KN-3 cells. (a, c, e) Alizarin Red S staining of KN-3 cells cultured in DM containing DA with or without $\operatorname{SCH} 23390(0.1,1$, and $10 \mu \mathrm{M})(\mathrm{a})$, sulpiride $(0.1,1$, and $10 \mu \mathrm{M})$ and clozapine $(0.001,0.01$, and $0.1 \mu \mathrm{M})(\mathrm{c})$, and $\mathrm{H} 89(0.01$, 0.1, and $1 \mu \mathrm{M})(\mathrm{e}) .(\mathrm{b}, \mathrm{d}, \mathrm{f})$ Positive areas of Alizarin red S-staining of each experiment were quantified using a Biozero digital microscope. Statistical analysis was performed using one-way ANOVA followed by Tukey's test. $\mathrm{n}=3,{ }^{* *} \mathrm{P}<0.01,{ }^{*} \mathrm{P}<0.05$. 

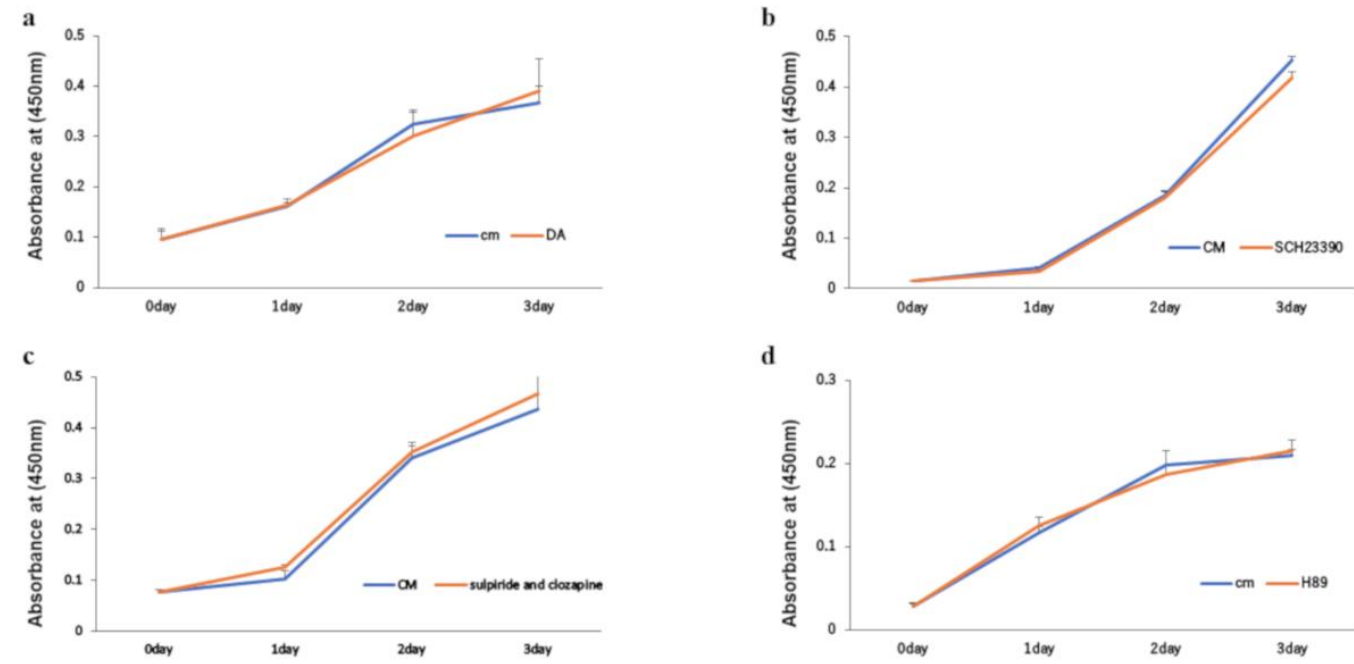

Supporting Information Figure 2 Effects of DA, SCH23390, sulpiride and clozapine, and $\mathrm{H} 89$ on the proliferation of KN-3 cells. Proliferation of KN-3 cells treated with DA $(10 \mu \mathrm{M})(\mathrm{a}), \mathrm{SCH} 23390(10 \mu \mathrm{M})(\mathrm{b})$, sulpiride $(10 \mu \mathrm{M})$ and clozapine $(0.1 \mu \mathrm{M})(\mathrm{c})$, and H89 $(1 \mu \mathrm{M})(\mathrm{d})$ was examined using WST-1 assays. Statistical analysis was performed using one-way ANOVA followed by Tukey's test. Absorbance was measured at $450 \mathrm{~nm}$. $\mathrm{n}=3$. 